\title{
The relationship among self-efficacy, perfectionism and academic burnout in medical school students
}

\author{
Ji Hye Yu', Su Jin Chae ${ }^{1,2}$ and Ki Hong Chang ${ }^{1}$ \\ ${ }^{1}$ Office of Medical Education and ${ }^{2}$ Department of Medical Humanities \& Social Medicine, Ajou University School \\ of Medicine, Suwon, Korea
}

Purpose: The purpose of this study was to examine the relationship among academic self-efficacy, socially-prescribed perfectionism, and academic burnout in medical school students and to determine whether academic self-efficacy had a mediating role in the relationship between perfectionism and academic burnout.

Methods: A total of 244 first-year and second-year premed medical students and first- to fourth-year medical students were enrolled in this study. As study tools, socially-prescribed perfectionism, academic self-efficacy, and academic burnout scales were utilized. For data analysis, correlation analysis, multiple regression analysis, and hierarchical multiple regression analyses were conducted. Results: Academic burnout had correlation with socially-prescribed perfectionism. It had negative correlation with academic self-efficacy. Socially-prescribed perfectionism and academic self-efficacy had 54\% explanatory power for academic burnout. When socially-prescribed perfectionism and academic self-efficacy were simultaneously used as input, academic self-efficacy partially mediated the relationship between socially-prescribed perfectionism and academic burnout.

Conclusion: Socially-prescribed perfectionism had a negative effect on academic self-efficacy, ultimately triggering academic burnout. This suggests that it is important to have educational and counseling interventions to improve academic self-efficacy by relieving academic burnout of medical school students.

Key Words: Perfectionism, Socially prescribed perfectionism, Academic self-efficacy, Academic burnout

\section{Introduction}

Many students who were at the top of their class at high school have experienced disappointment over their academic scores in medical school. They often have extreme stress caused by overloaded studies and anxiety over worries of failing courses, subsequently leading to their loss of self-confidence or feeling inferior. This seems to be especially true for those students who have advanced to medical school because of excellent high school grades or expectations and persuasion by parents or close friends. They usually lack self-motivation for medical school studies, thus experiencing academic difficulties [1]. Active investigations into Korean academic burnout of medical students began after 2012. A few studies have attempted to determine the relationship between perfectionism and academic burnout or between self-efficacy and academic burnout [2,3], hence elucidating causative variables of academic burnout in medical
Received: November 17, 2015 • Revised: December 3, 2015 - Accepted: December 8, 2015 Corresponding Author: Su Jin Chae (http://orcid.org/0000-0003-3060-8933)

Department of Medical Humanities \& Social Medicine, Ajou University School of Medicine, 164 Worldcup-ro, Yeongtong-gu, Suwon 16499, Korea

Tel: +82.31.219.4511 Fax: +82.31.219.4093 email: edujin@ajou.ac.kr
Korean J Med Educ 2016 Mar; 28(1): 49-55.

http://dx.doi.org/10.3946/kjme.2016.9

eISSN: 2005-7288

(C) The Korean Society of Medical Education. All rights reserved. This is an open-access article distributed under the terms of the Creative Commons Attribution Non-Commercial License (http:// creativecommons.org/licenses/by-nc/3.0/), which permits unrestricted non-commercial use, distribution, and reproduction in any medium, provided the original work is properly cited. 
students.

In this study, we focused on maladaptive variables that might have threatened the psychological well-being of medical students to search for psychological variables that may decrease academic burnout through studying the relationship between socially-prescribed perfectionism and academic burnout. As one of the dimensions of perfectionism, socially-prescribed perfectionism is characterized by acknowledgement of unreal and impractical assignment of academic goals not by the student themselves, but by others or by the fear of negative judgment by others [4]. Academic burnout consists of physical, emotional, and psychological depletion due to fatigue, frustration, distance from studies, stress, helplessness, and cynical attitude as a result of academic overload [2]. In a prior study [5], it was observed that academic burnout was a major causative variable for school maladjustment. In addition, academic burnout was found to be closely related to perfectionism [5]. Numerous investigations have revealed that perfectionism tendencies and academic burnout are significantly static correlated [6]. It is representative variable that can aggravates negative results caused by stress and a variable that may enhance academic burnout [7].

Perfectionism and academic self-efficacy have been confirmed as main variables that can affect academic burnout [1]. That is, academic self-efficacy can influence the performance of students. It is also an individual variable that can significantly predict academic achievement. In this context, academic self-efficacy is explained as an overall judgment, including self-ability to manipulate and effectuate required series of academically related tasks [8]. In other words, individuals with high academic self-efficacy will select challenging task and put in further effort in order to successfully complete the task. When confronted with difficult obstacles, they will persevere to accomplish the tasks in spite of barriers. In addition, high degrees of academic self-efficacy can lead to lower levels of anxiety and hence excellent self-control abilities. It can be surmised that academic self-efficacy may decrease academic burnout as a consequence of socially-prescribed perfectionism. Therefore, the objectives of this study were (1) to determine whether medical students' sociallyprescribed perfectionism could affect academic burnout, and (2) to understand whether academic self-efficacy could mediate the relationship between sociallyprescribed perfectionism and academic burnout.

\section{Subjects and methods}

\section{Subject}

A total of 227 first-year and second-year premed medical students and first- to fourth-year medical students who replied to questionnaire were enrolled in this study. Three were excluded from this study due to errors in replying. Therefore, a total of 224 replies were used for this study. The questionnaire used in this study was conducted between October 28 and September 9, 2015. Each questionnaire needed approximately 15 minutes to complete. The distribution of class year and gender of participants are shown in Table 1.

\section{Measures}

\section{1) Socially-prescribed perfectionism}

In order to measure socially-prescribed perfectionism, multidimensional perfectionism scale developed by Hewitt \& Flett [9] and adapted by Lee [10] was employed. This scale comprised of three subscales: selforiented perfectionism, socially-prescribed perfectionism, and other-oriented perfectionism. Each subscale comprised of 15 items. Therefore, it had a total of 
Table 1. Distribution of Class Year and Age of Medical Students

\begin{tabular}{|c|c|c|c|}
\hline \multirow{2}{*}{ Year } & \multicolumn{2}{|c|}{ Gender } & \multirow{2}{*}{ Total } \\
\hline & Male & Female & \\
\hline Premedical students 1 & 27 (18.00) & $5(6.58)$ & 32 (14.29) \\
\hline Premedical students 2 & $13(8.78)$ & $10(13.16)$ & $23(10.27)$ \\
\hline Medical students 1 & 28 (18.92) & $19(25.00)$ & 47 (20.98) \\
\hline Medical students 2 & $26(17.57)$ & $14(18.42)$ & $40(17.86)$ \\
\hline Medical students 3 & 25 (16.89) & $14(18.42)$ & 39 (17.41) \\
\hline Medical students 4 & $29(19.59)$ & $14(18.42)$ & $43(19.20)$ \\
\hline Total & $148(100.00)$ & $76(100.00)$ & $224(100.00)$ \\
\hline
\end{tabular}

Data are presented as number $(\%)$.

45 questionnaire items (e.g., "My family expects me to be perfect"). Five-point Likert Scale was used to score for each item, ranging from "strongly disagree" (1 point) to "strongly agree" (5 points). Higher points indicated higher degrees of perfectionism inclination. In this study, we only used 15 items directly related to "socially-prescribed perfectionism." Its Cronbach $\alpha$ value was 0.794 .

\section{2) Academic self-efficacy}

Academic self-efficacy was assessed using the scale developed by Kim \& Park [8]. This scale consisted of a total of 28 items in the following three subscales: self-confidence (e.g., "I feel anxious when I speak in front of the class"), self-regulatory efficacy (e.g., "I usually make a plan for studying and adhere to the plan"), and task difficulty preference (e.g., "I enjoy challenging complex problems"). The 5-point Likert Scale system was used. Higher scores indicated higher academic self-efficacy. The academic self-efficacy Cronbach $\alpha$ value was 0.901 . The Cronbach $\alpha$ values for subscales of self-confidence, self-regulatory efficacy, and task difficulty preference were $0.717,0.740$, and 0.759 , respectively.

\section{3) Academic burnout}

Academic burnout was measured using the Maslach Burnout Inventory-Student Survey (MBI-SS) academic burnout scale developed by Lee \& Lee [11]. This scaling system had a total of 14 items, including five items of emotional exhaustion (e.g., "I feel stressed and exhausted from studying"), five items of inefficacy (e.g., "I know how to effectively relieve stress from studying"), and four items of cynicism (e.g., "I am not sure if what I am studying now is necessary"). Each item was scored using the 5-point Likert scaling system. Higher points were interpreted as having a higher likelihood of academic burnout. The Cronbach $\alpha$ value of academic burnout was 0.873. For subscales, the Cronbach $\alpha$ values for emotional exhaustion, inefficacy, and cynicism were 0.887, 0.762, and 0.782, respectively.

\section{Analysis}

First, correlation analysis was conducted to identify subscales. To determine whether academic self-efficacy could mediate the relationship between sociallyprescribed perfectionism and academic burnout, three steps of procedure suggested by Baron \& Kenny [12] was utilized. Obtained data were subjected to statistical analysis using SPSS version 12.0 (SPSS Inc., Chicago, USA). 


\section{Results}

\section{Correlations among socially-prescribed perfectionism, academic burnout, and academic self-efficacy}

The relationships among variables are summarized in Table 2. Socially-prescribed perfectionism was positively correlated $(r=0.428, \mathrm{p}<0.01)$ with academic burnout while academic self-efficacy was negatively correlated $(r=-0.727, p<0.01)$ with academic burnout. All subscales of academic self-efficacy showed negative correlations with academic burnout, including self-confidence $(r=$ -0.609, $\mathrm{p}<0.01)$, self-regulatory efficacy $(\mathrm{r}=-0.675, \mathrm{p}<$ $0.01)$, and task difficulty preference $(r=-0.737, p<0.01)$.
In addition, there was a negative correlation $(r=-0.453$, $\mathrm{p}<0.01$ ) between socially-prescribed perfectionism and academic self-efficacy.

\section{Effect of socially-prescribed perfectionism and academic self-efficacy on academic burnout}

Multiple regression analysis was performed to evaluate the effect of socially-prescribed perfectionism and academic self-efficacy on academic burnout. The results are shown in Table 3. Socially-prescribed perfectionism and academic self-efficacy could explain 54\% (F= 128.354, $\mathrm{p}<0.001)$ for academic burnout. Both sociallyprescribed perfectionism $(\beta=0.123, \mathrm{p}<0.05)$ and academic self-efficacy $(\beta=-0.674, \mathrm{p}<0.001)$ could significantly predict academic burnout.

Table 2. Descriptive Statistics and Correlations for the Measures

\begin{tabular}{lccccccccc}
\hline & 1 & 2 & 3 & 4 & 5 & 6 & 7 & 8 & 9 \\
\hline 1 & 1 & & & & & & & & \\
2 & $-0.374^{* *}$ & 1 & & & & & & & \\
3 & $-0.447^{* *}$ & $0.763^{* *}$ & 1 & & & & & & \\
4 & $-0.444^{* *}$ & $0.760^{* *}$ & $0.836^{* *}$ & 1 & & & & & \\
5 & $-0.453^{* *}$ & $0.909^{* *}$ & $0.935^{* *}$ & $0.935^{* *}$ & 1 & & & & \\
6 & $0.353^{* *}$ & $-0.490^{* *}$ & $-0.566^{* *}$ & $-0.619^{* *}$ & $-0.602^{* *}$ & 1 & & & \\
7 & $0.288^{* *}$ & $-0.663^{* *}$ & $-0.650^{* *}$ & $-0.680^{* *}$ & $-0.719^{* *}$ & $0.419^{* *}$ & 1 & & \\
8 & $0.349^{* *}$ & $-0.339^{* *}$ & $-0.413^{* *}$ & $-0.475^{* *}$ & $-0.440^{* *}$ & $0.511^{* *}$ & $0.346^{* *}$ & 1 & \\
9 & $0.428^{* *}$ & $-0.609^{* *}$ & $-0.675^{* *}$ & $-0.737^{* *}$ & $-0.727^{* *}$ & $0.856^{* *}$ & $0.686^{* *}$ & $0.803^{* *}$ & 1 \\
Mean & 2.737 & 3.244 & 3.167 & 3.245 & 3.221 & 2.874 & 2.790 & 2.888 & 2.854 \\
SD & 0.426 & 0.518 & 0.509 & 0.519 & 0.478 & 0.889 & 0.589 & 0.786 & 0.599 \\
\hline
\end{tabular}

1: Socially-prescribed perfectionism, 2: Self-confidence, 3: Self-regulatory efficacy, 4: Task difficulty preference, 5: Academic self-efficacy, 6: Emotional exhaustion, 7: Inefficacy, 8: Cynicism, 9: Academic burnout, SD: Standard deviation. ${ }^{* *} \mathrm{p}<0.01$.

\section{Table 3. Multiple Regression Analysis of Socially-Prescribed Perfectionism and Academic Self-Efficacy on Academic Burnout}

\begin{tabular}{|c|c|c|c|c|}
\hline \multirow{2}{*}{ Independent variable } & \multicolumn{2}{|c|}{ Unstandardized coefficients } & Standardized coefficients & \multirow{2}{*}{$\mathrm{t}$} \\
\hline & $\mathrm{B}$ & SE & $\beta$ & \\
\hline Socially-prescribed perfectionism & 0.173 & 0.073 & 0.123 & $2.386^{*}$ \\
\hline Academic self-efficacy & -0.841 & 0.064 & -0.674 & $-13.044^{* * *}$ \\
\hline \multicolumn{5}{|c|}{$R^{2}=0.544$, adj. $R^{2}=0.540, F=128.354^{* * *}$} \\
\hline
\end{tabular}

${ }^{*} p<0.05,{ }^{* * *} p<0.001$. 
Table 4. Hierarchical Multiple Analysis for Examining the Mediating Effect of Academic Self-Efficacy

\begin{tabular}{|c|c|c|c|c|c|c|c|c|}
\hline \multirow{2}{*}{$\begin{array}{l}\text { Dependent } \\
\text { variable }\end{array}$} & \multirow{2}{*}{$\begin{array}{l}\text { Independent } \\
\text { variable }\end{array}$} & \multicolumn{2}{|c|}{$\begin{array}{c}\text { Unstandardized } \\
\text { coefficients }\end{array}$} & \multirow{2}{*}{$\begin{array}{c}\begin{array}{c}\text { Standardized } \\
\text { coefficients }\end{array} \\
\beta\end{array}$} & \multirow[t]{2}{*}{$\mathrm{t}$} & \multirow{2}{*}{$\begin{array}{c}R^{2} \\
\text { (Adj. } R^{2} \text { ) }\end{array}$} & \multirow[t]{2}{*}{$\Delta^{2}$} & \multirow[t]{2}{*}{$F$} \\
\hline & & B & SE & & & & & \\
\hline $\begin{array}{l}\text { Academic } \\
\text { self-efficacy }\end{array}$ & $\begin{array}{l}\text { Socially-prescribed } \\
\text { perfectionism }\end{array}$ & -0.510 & 0.068 & -0.453 & $-7.487^{* * *}$ & $\begin{array}{l}0.205 \\
(0.202)\end{array}$ & & $56.057^{* * *}$ \\
\hline \multirow[t]{3}{*}{$\begin{array}{c}\text { Academic } \\
\text { burnout }\end{array}$} & $\begin{array}{l}\text { Socially-prescribed } \\
\text { perfectionism }\end{array}$ & 0.602 & 0.086 & 0.428 & $6.968 * * *$ & $\begin{array}{l}0.184 \\
(0.180)\end{array}$ & & $48.551^{* * *}$ \\
\hline & $\begin{array}{l}\text { Socially-prescribed } \\
\text { perfectionism }\end{array}$ & 0.173 & 0.073 & 0.123 & $2.386^{*}$ & $\begin{array}{l}0.544 \\
(0.540)\end{array}$ & 0.360 & $128.354^{* * *}$ \\
\hline & $\begin{array}{l}\text { Academic } \\
\text { self-efficacy }\end{array}$ & -0.841 & 0.064 & -0.674 & $-13.044^{* * *}$ & & & \\
\hline
\end{tabular}

${ }^{*} \mathrm{p}<0.05,{ }^{* * *} \mathrm{p}<0.001$.

\section{Mediating effect of academic self-efficacy on the relationship between socially- prescribed perfectionism and academic burnout}

Hierarchical multiple analysis results are shown in Table 4. The socially-prescribed perfectionism could significantly $(\beta=0.428, \quad \mathrm{p}<0.001) \quad$ explain academic burnout. When both socially-prescribed perfectionism and academic self-efficacy were used as input simultaneously, the $\beta$-value of socially-prescribed perfectionism on academic burnout was significantly $(\mathrm{p}<0.05)$ decreased from 0.428 to 0.123 . These results revealed that academic self-efficacy could partially mediate the relationship between socially-prescribed perfectionism and academic burnout. Sobel test revealed that academic self-efficacy could significantly $(Z=6.810, \quad p<0.001)$ mediate the relationship between socially-prescribed perfectionism and academic burnout.

\section{Discussion}

A typical representative example of a person who is expected to be perfect not only by himself or herself, but also by parents, teachers, and the community is medical student. These individuals socially experience strong achievement motivation for perfectionism. They receive frequent praises and messages from the society that perfectionism is good [13]. According to previous studies, such perfectionism tendencies can predict positive or negative adaptation to school life according to whether the tendency is expressed positively or negatively. It has been found that perfectionism is closely related to academic self-efficacy which can determine self-ability and self-confidence $[3,14]$. Therefore, it is of great interest to clarify the relationships among perfectionism tendency, academic burnout, and academic self-efficacy to find variables that can reduce academic burnout.

In the present study, we investigated the relationship between socially-prescribed perfectionism and academic burnout in medical students. We also determined whether academic self-efficacy might mediate the relationship between socially-prescribed perfectionism and academic burnout. Our results are summarized in the following.

First, there was a significant correlation $(\mathrm{r}=0.428)$ between academic burnout and socially-prescribed perfectionism. There was also a significant negative 
Ji Hye Yu, et al: The relationship among self-efficacy, perfectionism and academic burnout

correlation $(\mathrm{r}=-0.727)$ between academic burnout and academic self-efficacy, demonstrating a close relationship between socially-prescribed perfectionism and academic burnout or academic self-efficacy in medical students. That is, when socially-prescribed perfectionism inclination is high but academic self-efficacy is low, there is an increased risk of academic burnout. Our results are in agreement with a previous report [1] about a negative correlation $(\mathrm{r}=-0.59)$ between academic burnout and academic self-efficacy. The observation that academic self-efficacy is more related to academic burnout than socially-prescribed perfectionism suggests that academic self-efficacy is an effective predictor for academic performance. Therefore, it is of critical importance to have education or counseling programs to enhance academic self-efficacy in medical students who experience academic burnout.

Second, multiple regression analysis was performed to determine the effect of socially-prescribed perfectionism and academic self-efficacy on academic burnout. Our results showed that academic burnout could be predicted by both socially-prescribed perfectionism $(\beta=$ $0.123, \mathrm{p}<0.05)$ and academic self-efficacy $(\beta=-0.674$, $\mathrm{p}<0.001$ ), with academic self-efficacy having greater significance, suggesting that academic self-efficacy might play a greater role than socially-prescribed perfectionism in academic burnout of medical students.

Third, hierarchical multiple analysis was conducted in this study to determine whether academic self-efficacy could mediate the relationship between sociallyprescribed perfectionism and academic burnout. The results showed that academic self-efficacy could indeed mediate the relationship between socially-prescribed perfectionism and academic burnout. Academic selfefficacy psychologically lowered socially-prescribed perfectionism and academic self-efficacy, consequently leading to academic burnout. In other words, medical students with higher maladaptive academic perfectionism are at increased risk of having academic burnout. Academic self-efficacy acting as a psychological resource may decrease the chances of academic burnout. Other prior reports have also shown that sociallyprescribed perfectionism can negatively affect academic self-efficacy $[15,16]$. These studies have also suggested that medical students' socially-prescribed perfectionism inclinations itself not only can elicit academic burnout, but also can have negatively affect academic selfefficacy, thus promoting academic burnout. Hence, methods that can help medical students overcome socially-prescribed perfectionism while enhancing academic self-efficacy are needed.

In this study, we focused on variables such as sociallyprescribed perfectionism and academic self-efficacy that could influence medical students. We also attempted to describe the significance of academic self-efficacy in mediating the relationship between socially-prescribed perfectionism and academic burnout in order to find solutions to prevent academic burnout. We confirmed that academic self-efficacy was a significant variable that could influence individual psychological variables associated with study abilities.

One of the limitations of this study is that only a specific group of students in a single educational institution was included in the present study. Another limitation is that a higher number of variables that may affect academic burnout should have been included and analyzed in this study to improve the statistical power. An ideal study design should encompass a diverse range of individual internal and external variables that might affect academic burnout so that structural relationships can be demonstrated. Nonetheless, this study provides basic information for medical students to avoid academic burnout. 
Acknowledgements: None.

Funding: None.

Conflicts of interest: None.

\section{References}

1. Lee SH, Jeon WT. The relationship between academic self-efficacy and academic burnout in medical students. Korean J Med Educ 2015; 27: 27-35.

2. Chun KH, Park YS, Lee YH, Kim SY. Academic burnout and selection-optimization-compensation strategy in medical students. Korean J Med Educ 2014; 26: 299-308.

3. Ahn D, Kim O. Perfectionism, achievement goals, and academic efficacy in medical students. Korean J Med Educ 2006; 18: 141-152.

4. Kim SJ, Lee SY. The relationship between sociallyprescribed perfectionism and anger suppression in college students: self-silencing as a mediator. Korean J Couns 2014; 15: 729-751.

5. Lee HA, Jo HI. The relation among perfectionism, academic engagement and academic burnout: the mediating effects of motives and goal processes. Korean J Couns Psychother 2013; 25: 575-601.

6. Han KS, Hwang EH. The relationship between perfectionism and school adjustment of gifted and general students: mediating effect of self-efficacy. J Yeolin Educ 2010; 18: 27-45.

7. Hill AP, Hall HK, Appleton PR. Perfectionism and athlete burnout in junior elite athletes: the mediating role of coping tendencies. Anxiety Stress Coping 2010; 23:
415-430.

8. Kim AY, Park IY. Construction and validation of academic self-efficacy scale. Korean J Educ Res 2001; 39: 95-123.

9. Hewitt PL, Flett GL. Perfectionism in the self and social contexts: conceptualization, assessment, and association with psychopathology. J Pers Soc Psychol 1991; 60: 456-470.

10. Lee MH. The positive and negative function of perfectionism: in relations with achievement goal, stress, psychological well-being and depression [master's thesis]. [Seoul, Korea]: Hanyang University; 2001.

11. Lee SH, Lee DY. Validation of the MBI-SS scales-based on medical school students. Asian J Educ 2013; 14: 165-187.

12. Baron RM, Kenny DA. The moderator-mediator variable distinction in social psychological research: conceptual, strategic, and statistical considerations. J Pers Soc Psychol 1986; 51: 1173-1182.

13. Silverman LK, Baska L. Counseling the gifted and talented. Denver, USA: Love Publishing; 1993.

14. Khu BY, Yoo JM. The effects of multidimensional perfectionism, self-efficacy and stress on school adaptation. Korean J Youth Couns 2007; 15: 67-76.

15. Shin JM, Park MS, Ham KA. The mediating effects of academic self-efficacy in the relationship between socially-prescribed perfectionism and speech anxiety children's. J Emot Behav Disabil 2014; 30: 23-43.

16. Jeon SM, Park JH. The effects of high school students' perfectionism on their academic procrastination: the moderating role of academic self-efficacy. Korean J Youth Stud 2014; 21: 589-612. 